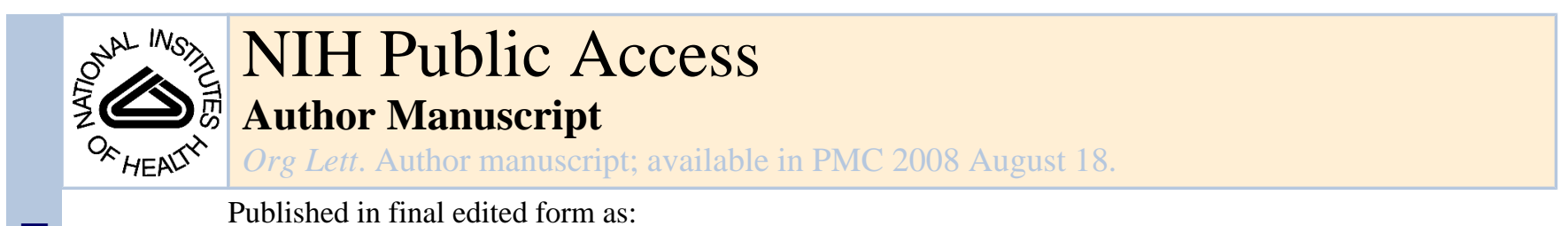

Published in final edited form as:

Org Lett. 2006 September 28; 8(20): 4645-4647.

\title{
Ring Expansion/Homologation-Aldehyde Condensation Cascade using tert-Trihalomethylcarbinols
}

\author{
J. R. Falck ${ }^{\dagger}$, Anyu He ${ }^{\dagger}$, L. Manmohan Reddy ${ }^{\dagger}$, Abhijit Kundu $^{\dagger}$, Deb K. Barma ${ }^{\dagger}$, A. \\ Bandyopadhyay ${ }^{\dagger}$, Sukanta Kamila ${ }^{\dagger}$, Radha Akella ${ }^{\dagger}$, Romain Bejot $^{\ddagger}$, and Charles \\ Mioskowski ${ }^{\ddagger}$ \\ Departments of Biochemistry and Pharmacology, University of Texas Southwestern Medical Center, \\ Dallas, Texas 75390 USA, and Laboratoire de Synthèse Bio-Organique, UMR 7175 - LC1, Faculté \\ de Pharmacie, Université Louis Pasteur, 74 Route du Rhin, BP 24, 67401 Illkirch, France
}

\begin{abstract}<smiles>CCC(C)(C)O</smiles>

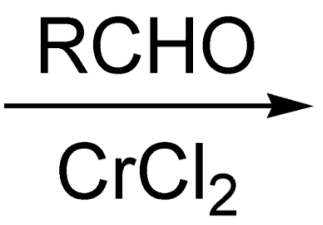

$\mathrm{X}=\mathrm{Cl}, \mathrm{Br}$

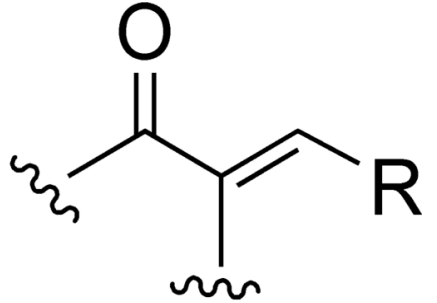

Treatment of cyclic tert-trihalomethylcarbinols with $\mathrm{CrCl}_{2}$ in THF/HMPA in the presence of aryl or aliphatic aldehydes initiates a cascade sequence of one carbon ring expansion-olefination affording conjugated exo-cyclic ketones. Acyclic tert-trihalomethylcarbinols undergo a comparable cascade of one carbon homologation-olefination.
\end{abstract}

Trihalomethylcarbinols and their derivatives are a diverse ${ }^{1}$ and readily accessible class of functionalized alcohols. ${ }^{2}$ Their reduction, inter alia, electrochemical, ${ }^{3}$ zero-valent metals/ metal salts, ${ }^{4}$ or aqueous $\mathrm{Cr}(\mathrm{II}),{ }^{5}$ principally induces elimination to the corresponding 1,1dihaloölefin. However, our laboratories recently observed that sec-trihalomethylcarbinol derivatives follow a different reaction manifold when reduced with $\mathrm{Cr}$ (II) salts in THF leading stereoselectively to $(Z)$ - $\alpha$-haloenol esters and (Z)- $\beta$-haloenol ethers. ${ }^{6}$ We consequently examined the behavior under similar conditions of tert-trihalomethylcarbinols in the presence of aldehydes and report herein a cascade sequence ${ }^{7}$ of one carbon ring expansion/ homologation-olefination affording conjugated ketones. ${ }^{8}$

The cascade sequence was optimized using carbinol $\mathbf{1}^{9}(\mathrm{X}=\mathrm{Cl})$ and benzaldehyde $\mathbf{2}$ as the test system. The best yield of adduct $3^{10}$ was obtained using $\mathrm{CrCl}_{2}$ (6 equiv) in THF/HMPA (2:1) at $40{ }^{\circ} \mathrm{C}$ (Table 1 , entry 1$)$. Using the tribromo-version of $\mathbf{1}(\mathrm{X}=\mathrm{Br})$, the results were identical, except the reaction only required $2 \mathrm{~h}$ instead of the $4 \mathrm{~h}$ when $\mathrm{X}=\mathrm{Cl}$. The output of

\footnotetext{
j.falck@utsouthwestern.edu; mioskow@aspirine.u-strasbg.fr.

University of Texas Southwestern.

‡Université Louis Pasteur.

Supporting Information Available Synthetic procedures, analytical data, $\mathrm{X}$-ray files, and ${ }^{1} \mathrm{H} /{ }^{13} \mathrm{C}$ spectra for all new compounds. This material is available free of charge via the Internet at http://pubs.acs.org.
} 
3 did not improve using a lower THF/HMPA ratio (i.e., 1:1) and it decreased linearly as the ratio increased in favor of THF. Other solvents or their combinations, e.g., THF only, DMF, EtOAc, dioxane, and HMPA, were not satisfactory. There was also a strict dependence on the amount of $\mathrm{CrCl}_{2} ; 5$ and 4 equivalents gave 3 in $51 \%$ and $30 \%$ yield, accordingly. Efforts to use fewer equivalents of $\mathrm{CrCl}_{2}$ by coupling the reaction to a regeneration system showed promise, but clearly need further improvement. For instance, under otherwise identical conditions as entry $1, \mathrm{CrCl}_{2}$ (1 equiv)/Mn powder ( 8 equiv) and $\mathrm{CrCl}_{2}$ (1 equiv)/Fe powder (10 equiv) gave rise to 3 in $58 \%$ and $42 \%$ yield, respectively.

We were gratified to find that the cascade was also applicable to aliphatic (entry $2, \mathbf{4} \rightarrow \mathbf{5}^{10}$ ), $\alpha, \beta$-unsaturated (entry $3, \mathbf{6} \rightarrow \mathbf{7}^{10}$ ), and electron rich (entry $4, \mathbf{8} \rightarrow \mathbf{9}^{10}$ and entry $5, \mathbf{1 0} \rightarrow$ $11^{11}$ ) aldehydes. In all, only exo-cyclic olefins were generated including 5 , the thermodynamically less stable positional isomer. Notably, the yield of adduct, as demonstrated in the condensation of $\mathbf{1}$ with $\mathbf{1 0}$ (entry 5), could be ameliorated utilizing a modest excess (1.5 equiv) of carbinol. Electron deficient aldehydes were also suitable substrates, e.g., $\mathbf{1 2} \rightarrow \mathbf{1 3}$ (entry 6). Contrary to expectations, ${ }^{8}$ the ring enlargement-olefination of $\mathbf{1 4}$ favored $\mathbf{1 5}, 12$ the product of migration of the less substituted carbon, over $\mathbf{1 6}^{13}$ by a $5: 1$ ratio (entry 7). Other ring sizes could be accommodated as well: cyclobutyl carbinol 17 evolved cyclopentenone $\mathbf{1 8}^{10}$ (entry 8 ) and cyclohexyl carbinol $19^{9 \mathrm{~b}}$ furnished cycloheptenone $\mathbf{2 0}^{10}$ (entry 9). To gain some insight into the influence of relative stereochemistry and conformation on the efficiency of the ring expansion process, the conformationally constrained erythro/threo-pairs 21/22 (entry 10) and $\mathbf{2 4 / 2 5}$ (entry 11) were subjected to the standard reaction conditions. The erthyro-isomers $\mathbf{2 1}$ and $\mathbf{2 4}$, whose trichloromethyls are equatorially disposed, afforded significantly greater yields of the expected adducts $\mathbf{2 3}$ and $\mathbf{2 6}$, respectively, consistent with better orbital overlap in the transition state. Simple elimination to the corresponding 1,1dichloroolefin accounted for the majority of the remaining material balance in all of these cases. Finally, comparable homologation-olefinations could be achieved using acyclic trihalocarbinols as evident by the isolation of $\mathbf{2 8}$ in good overall yield from the commercial carbinol 27 (entry 12).

While the mechanistic details have not been established, at least two pathways seem plausible in light of the existing data (Scheme 1). Initial metallation of the trihalomethyl moiety generates the key dihalochromium intermediate 29. A second round of metallation leads to $\mathbf{3 0}, 6$ which rearranges to dichromium ketone $\mathbf{3 1}$. The latter may exist as the dichromium enolate $\mathbf{3 7}$. Either would be expected to add rapidly to the aldehyde and collapse to the final product, $\mathbf{3 3}$.

Alternatively, $\alpha$-elimination of $\mathbf{2 9}$ forms carbene $\mathbf{3 4}$ and hence $\alpha$-haloenol 35, its rearrangement product. Addition to the aldehyde culminates in $\mathbf{3 3}$ via reduction of adduct $\mathbf{3 6}$. When an equimolar mixture of 2-chlorocyclohexanone and 2 was added to excess $\mathrm{CrCl}_{2}$ in THF/HMPA (2:1), $\mathbf{3}$ was isolated in only $34 \%$ yield. This suggests the keto tautomer of $\mathbf{3 5}$, i.e., $\mathbf{3 8}$, does not make a significant contribution to product formation.
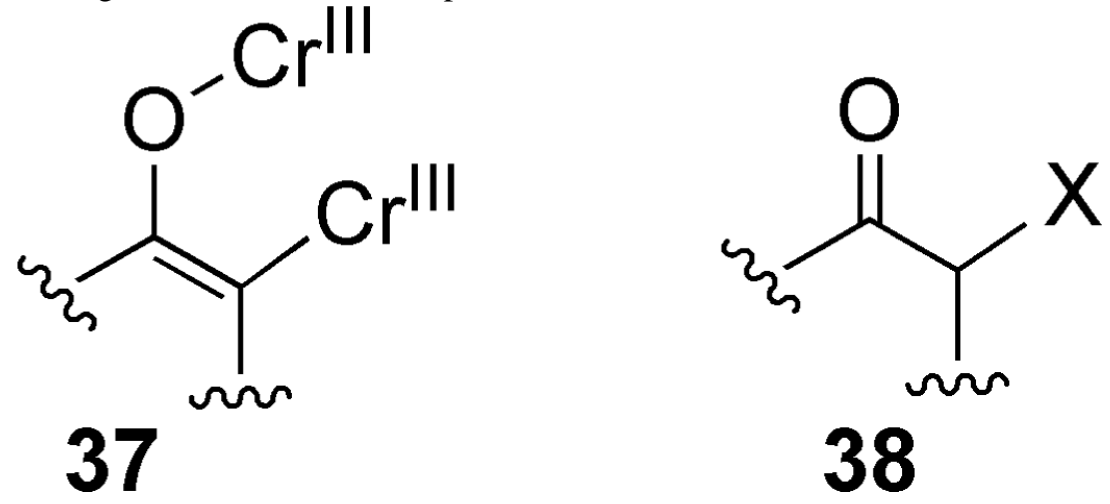

Org Lett. Author manuscript; available in PMC 2008 August 18. 


\section{Supplementary Material}

Refer to Web version on PubMed Central for supplementary material.

\section{Acknowledgment}

Financial support provide by the Robert A. Welch Foundation and NIH (GM31278, DK38226).

\section{References}

1. For example see: a Kiehlmann E, Loo P-W. Can. J. Chem 1969;47:2029-2037. b Corey EJ, Link JO. Tetrahedron Lett 1992;33:3431-3434. c Khrimian AP, Oliver JE, Waters RM, Panicker S, Nicholson JM, Klun JA. Tetrahedron: Asymmetry 1996;7:37-40. d Wang Z, Campagna S, Yang K, Xu G, Pierce ME, Fortunak JM, Confalone PN. J. Org. Chem 2000;65:1889-1891. [PubMed: 10750498] e Reeve W, Barron ER. J. Org. Chem 1975;40:1917-1920.

2. a Aggarwal VK, Mereu A. J. Org. Chem 2000;65:7211-7212. [PubMed: 11031052] b Taguchi H, Yamamoto H, Nozaki H. J. Am. Chem. Soc 1974;96:3010-3011. c Corey EJ, Link JO, Shao Y. Tetrahedron Lett 1992;33:3435-3438.

3. Shono T, Kise N, Yamazaki A, Ohmizu H. Tetrahedron Lett 1982;23:1609-1612.

4. a Kiehlmann E, Bianchi RJ, Reeve W. Can. J. Chem 1969;47:1521-1527. b Ranu BC, Samanta S, Das A. Tetrahedron Lett 2002;43:5993-5995. c Li J, Xu X, Zhang Y. Tetrahedron Lett 2003;44:9349_ 9351. d Farkas J, Kourim P, Sorm F. Coll. Czech. Chem. Commun 1959;24:2230-2236.

5. For seminal studies regarding the reactivity of polyhalogenated substrates with $\mathrm{Cr}$ (II) see, Wolf R, Steckhan E. J. Chem. Soc., Perkin Trans. 1 1986:733-739.

6. Bejot R, Tisserand S, Reddy LM, Barma DK, Baati R, Falck JR, Mioskowski C. Angew. Chem., Int. Ed. Engl 2005;44:2008-2011. [PubMed: 15726553]

7. For definition of cascade reactions and extensive examples see, Tietze LF, Beifuss U. Angew. Chem., Int. Ed. Engl 1993;32:131-163.

8. Review: HesseMRing Enlargement in Organic Chemistry1991VCHNew York

9. a Sibille S, d'Incan E, Leport L, Perichon J. Tetrahedron Lett 1986;27:3129. b Shono T, Kise N, Masuda M, Suzumoto T. J. Org. Chem 1985;50:2527.

10. Yanagisawa A, Goudu R, Arai T. Org. Lett 2004;6:4281. [PubMed: 15524463]

11. Sanchez IH, Larraza MI, Rojas I, Kuri Brena F, Flores HJ, Jankowski K. Heterocycles 1985;23:3033.

12. Trost BM, Schroeder GM. J. Am. Chem. Soc 1999;121:6759.

13. Kutulya LA, Kuz'min VE, Stel'makh IB, Khandrimalova TV, Shtifanyuk PP. J. Phys. Org. Chem 1992;5:308. 


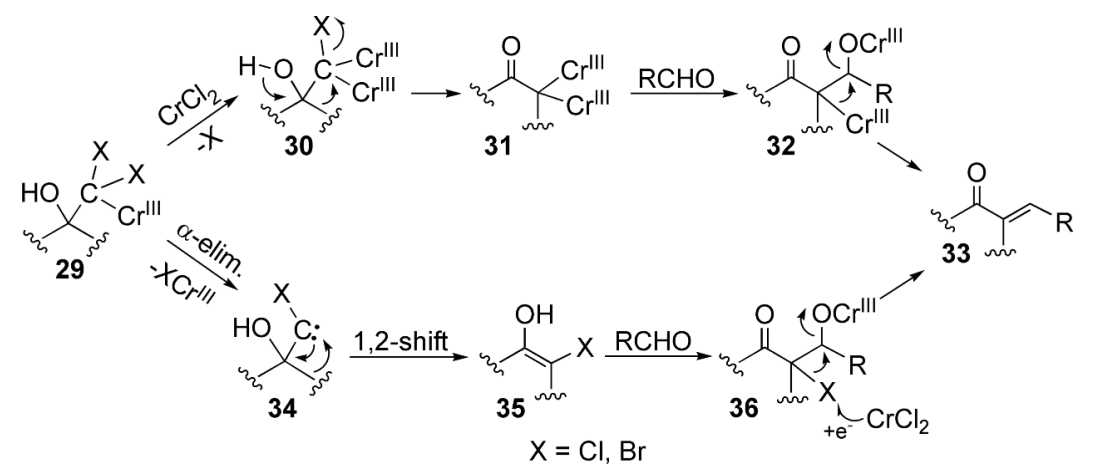

Scheme 1.

Proposed Cascade Mechanism. 
Table 1

Ring Expansion/Homologation-Aldehyde Condensation Cascade ${ }^{a}$

\begin{tabular}{|c|c|c|c|c|}
\hline entry & carbinol & aldehyde & product & yield $(\%)$ \\
\hline 1 & & $\begin{array}{c}\mathrm{PhCHO} \\
2\end{array}$ & & 72 \\
\hline 2 & & $\mathrm{Ph}_{4}^{\sim} \underset{\mathbf{C H O}}{\sim}$ & & 75 \\
\hline 3 & $\left(\mathrm{X}^{=} \mathrm{c}\right.$ & $\mathrm{Ph}_{6} \mathrm{CHO}$ & & 65 \\
\hline 4 & $\left(x^{=} \mathrm{Cl}\right)$ & & & 60 \\
\hline 5 & $\left(x^{=} \mathrm{Cl}\right)$ & & & $\begin{array}{l}74 \\
82^{c}\end{array}$ \\
\hline 6 & $(\mathrm{x} \stackrel{1}{=} \mathrm{Cl})$ & & & 49 \\
\hline 7 & & 2 & & $\begin{array}{l}50 \\
11\end{array}$ \\
\hline 8 & $\mathrm{CCl}_{3}$ & 2 & & 63 \\
\hline 9 & $\mathrm{H}$ & 2 & & 52 \\
\hline 10 & & 2 & & $\begin{array}{l}46 \\
38\end{array}$ \\
\hline 11 & $\mathrm{R}^{\mathrm{HO}}$ & 2 & & $\begin{array}{l}57 \\
20\end{array}$ \\
\hline 12 & 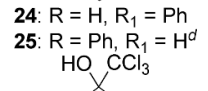 & 2 & & 70 \\
\hline
\end{tabular}

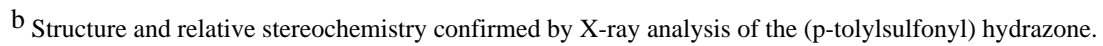

$\mathrm{d}$ Structure and relative stereochemistry confirmed by X-ray analysis.

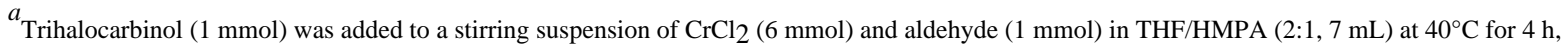
quenched with water and purified.

${ }^{c}$ Used 1.5 equivalents of carbinol. 